\title{
Insulated fixation system of plasma facing components to the divertor cassette in Eurofusion-DEMO
}

\author{
${\text { Vito Imbriani*a }{ }^{*} \text { Ugo Bonavolontà }}^{\mathrm{a}}$, Giuseppe Di Gironimo ${ }^{\mathrm{a}}$, Samir El Shawish ${ }^{\mathrm{b}}$, Mike Fursdon ${ }^{\mathrm{c}}$, \\ Louis Giannone $^{\mathrm{d}}$, Domenico Marzullo ${ }^{\mathrm{a}}$, Giuseppe Mazzone ${ }^{\mathrm{e}}$, Eliseo Visca ${ }^{\mathrm{e}}$, Jeong-Ha You ${ }^{\mathrm{d}}$. \\ ${ }^{a}$ CREATE/University of Naples, Industrial Engineering, Piazzale Tecchio 80, 80125 Napoli, Italy \\ ${ }^{b}$ Jozef Stefan Institute, Jamova 39, SI-1000 Ljubljana, Slovenia \\ ${ }^{c}$ Culham Centre for Fusion Energy, Department of Central Engineering, Abingdon OX14 3DB, UK \\ ${ }^{d}$ Max Planck Institute of Plasma Physics, Boltzmann Str. 2, 85748 Garching, Germany \\ ${ }^{e}$ ENEA, Department of Fusion and Technology for Nuclear Safety and Security, Frascati, Italy
}

The design activities of an insulated Plasma Facing Components-Cassette Body (PFCs-CB) support has been carried out under the pre-conceptual design phase for Eurofusion-DEMO Work Package DIV-1 "Divertor Cassette Design and Integration" - Eurofusion Power Plant Physics \& Technology (PPPT) program.

The Eurofusion-DEMO divertor is a key in-vessel component with PFCs which directly interact with the plasma scrape-off layer. The PFCs have to cope with high heat loads, neutron irradiation and electromagnetic loads. The mechanical integrity of the PFCs and water cooling pipes can be jeopardized by high heat loads and by electromagnetic loads generated in a disruption event. In European-DEMO the possibility to estimate the heat load by measuring the relative thermocurrents is under investigation. In order to allow thermocurrents measurements, a divertor design option provides that PFCs are electrically insulated from $\mathrm{CB}$.

In this work authors aim to analyze the opportunity that the PFC-CB fixing system incorporates an electrical insulation system, thus acquiring also an important diagnostic role in the measurement of the thermocurrents and in the management of the current flows. The possible use of ceramic material (e.g. alumina) as the insulating layer between the support components is investigated.

Keywords: Eurofusion-DEMO, Divertor assembly, Divertor Plasma Facing Components fixation system.

\section{Introduction}

Within the program activity Horizon 2020 [1][2] EUROfusion Consortium is finalizing the Pre Conceptual Design phase of a demonstration fusion power reactor (DEMO).

The DEMO-divertor (Fig. 1) is a key component [3][4][5]. It directly interacts with plasma Scrape-Off Layer and it has to withstand to complex load combinations of different nature (thermal, mechanical, electromagnetic, neutron loads, etc.).

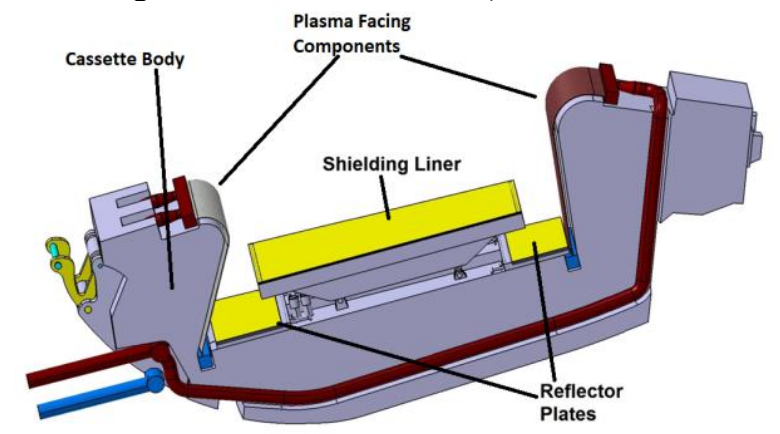

Fig. 1 CAD model of 2019 DEMO divertor assembly

The Plasma Facing Components-Cassette Body (PFCs-CB) fixing system (Fig. 2) has to cope with these loads ensuring the correct mechanical and thermal connection.

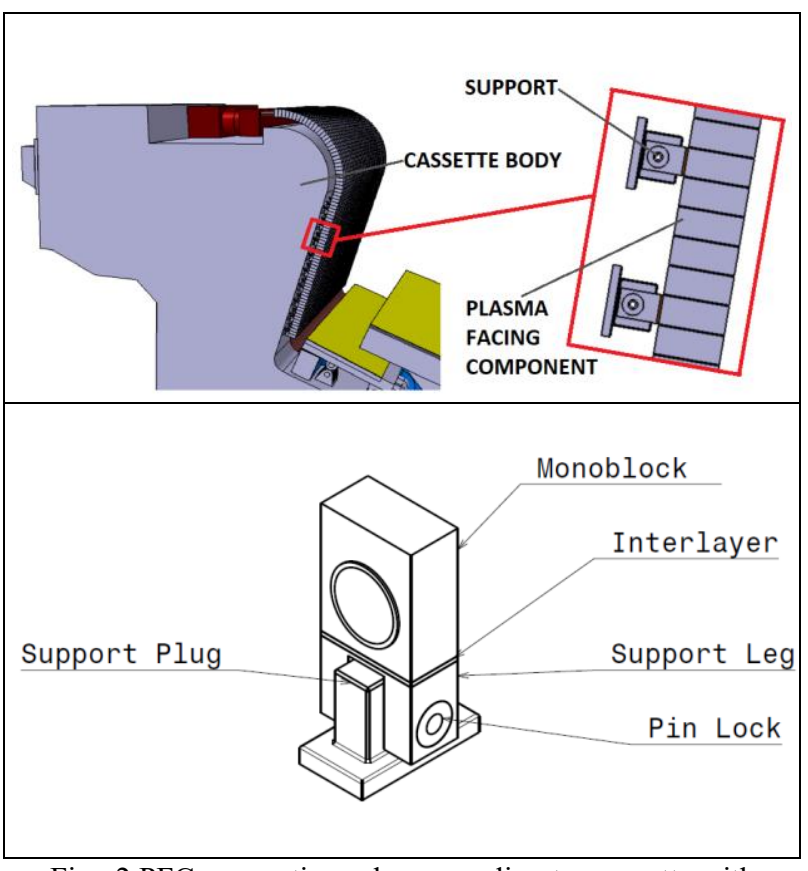

Fig. 2 PFC connection scheme on divertor cassette with isometric view of DEMO PFC-CB support

The heat load on PFCs must be controlled to prevent damage. It is possible to estimate the heat load by measuring the relative thermocurrents and it can be controlled introducing gas impurity in the plasma $[6][7][8]$. 


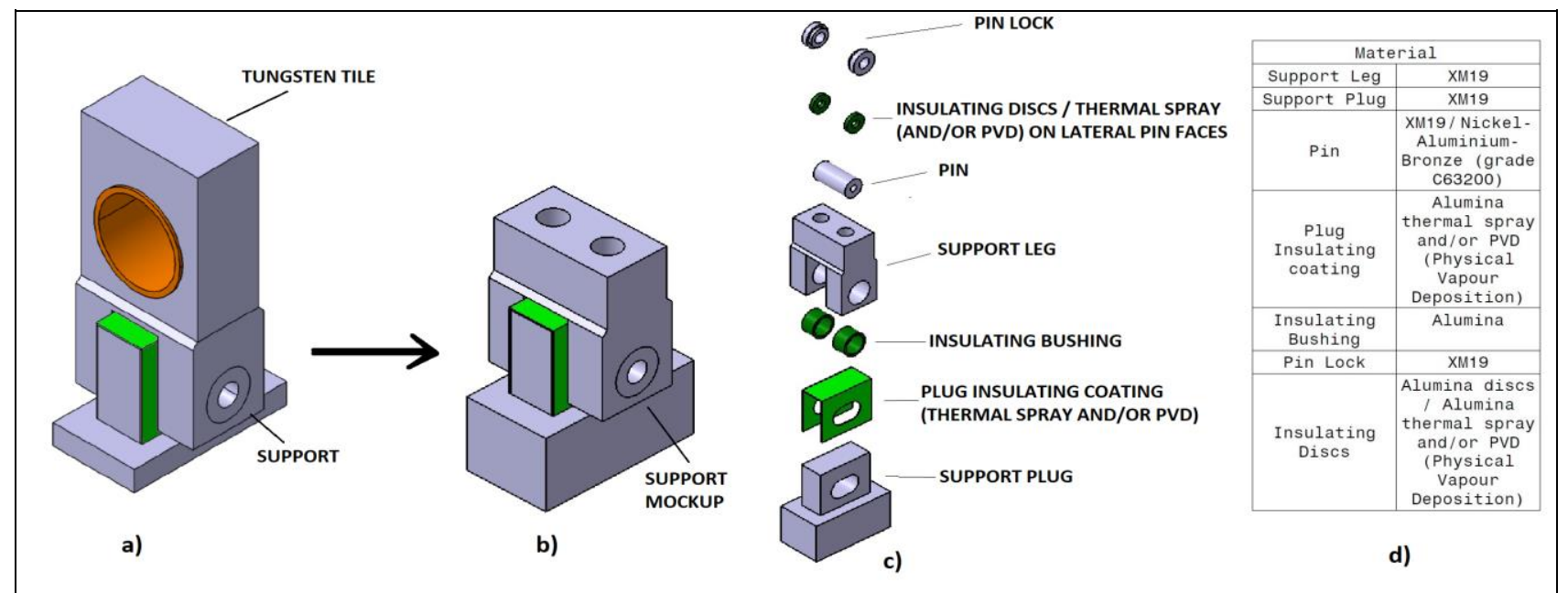

Fig. 3 a) DEMO PFC-CB support model $\quad$ b) Support mockup model c) Details on the components of the support mockup model d) Material table of the support mockup model

An isolated-PFCs divertor solution is a design option for reliable measurement of thermo-currents that are indirectly estimated as a voltage signal over a single resistive element (a shunt) attached to the CB [9][10]. Hence, it is necessary to develop an appropriate electrical insulation system between the PFCs and CB.

In this work authors aim to analyze the opportunity that the PFC-CB fixing system incorporates an insulation system, thus acquiring also an important diagnostic role in the measurement of the thermocurrents and in the management of the current flows (and relative Lorentz loads) in off-nominal operating conditions (e.g. Vertical Disruption Event_VDE).

The possible use of a ceramic material (e.g. alumina) as the insulating layer between the support components is investigated.

At this early stage of the study the preliminary dimensioning of the support is mainly influenced by the following requirements and design constraints:

- Capability to withstand electromagnetic traction loads of $9 \mathrm{kN}$

- Allow maintenance operations with relative disassembly of PFCs

- Allow thermal expansion of PFC

- Electrically insulate the PFCs from the Cassette

Taking into account these requirements, the first CAD model of the DEMO PFC-CB support was generated using CAE system CATIA V5 (Fig. 3_a). The design was influenced by the ITER Inner Vertical Target (IVT) PFCs to $\mathrm{CB}$ fixing support described in [11].

A future step of this analysis foresees the realization of a support mockup on which electrical and mechanical tests will be performed. The mockup is focused only on the support not considering the tungsten tile attached to it. Therefore a CAD model of the support mockup has been designed starting from the DEMO PFC-CB support model and this mockup model was used for the study (Fig. 3_b). To allow technical testing, the top and bottom area of the support mockup model have been modified as described in the next section. These geometrical changes are present only in the areas at the interface between PFC and CB but do not alter the general support configuration.

Afterwards a design optimization was performed in terms of mechanical behaviour by means of a 3D FEM (Finite Element Method) analysis using the Design Exploration package of ANSYS Workbench.

\section{Support geometry}

The support components that play the role of mechanical connection between $\mathrm{PFC}$ and $\mathrm{CB}$ are the Support Plug, the Support Leg and the Pin (Fig. 3_c).

The support plug consists of two rectangular parallelepipeds. The lower one is the base and in the DEMO model it will be first inserted in a dedicated hole designed inside the cassette surface and then welded. In the mockup support model, the height of the base has been increased by $10 \mathrm{~mm}$ and two M6 holes have been inserted in the lower face to allow mechanical and electrical tests (Fig. 4).

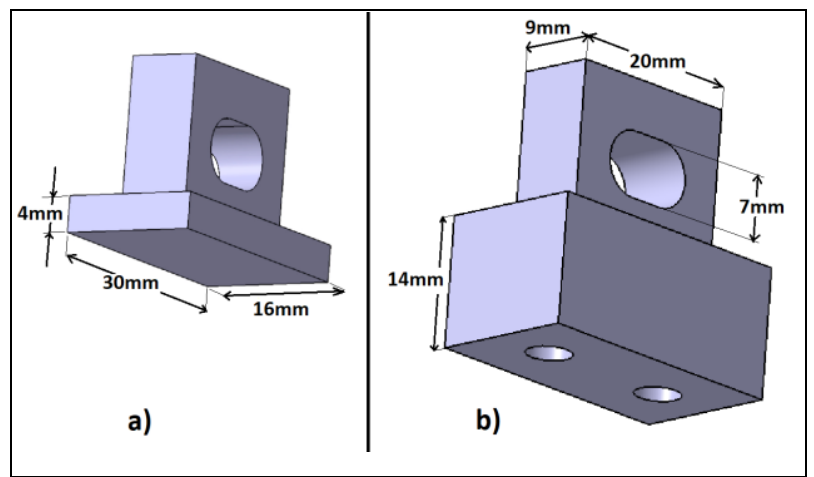

Fig. 4 a) DEMO model support plug, b) Mockup model support plug

In the upper part there is an elongated hole with a diameter of $7 \mathrm{~mm}$ that enables the pin to slide inside up to a length of $4 \mathrm{~mm}$, allowing thermal expansion of the PFC and avoiding related thermal stresses.

In Fig. 5 there is an isometric view of the Support Leg. On the left there is the DEMO model support leg and on 
the right there is the mockup model support leg. Similarly to the support plug, the upper part of the mockup support leg has also been extended by $10 \mathrm{~mm}$ and two M6 holes have been inserted in the upper face for the same reasons. In the DEMO support leg this extension is not present and the upper face is connected to the tungsten tile.

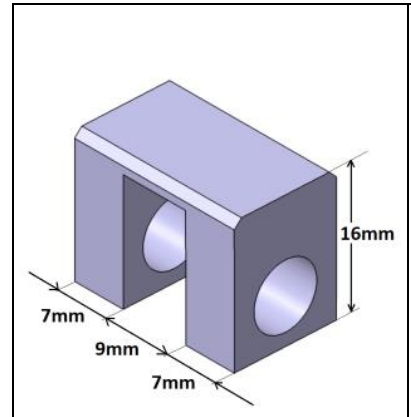

a)

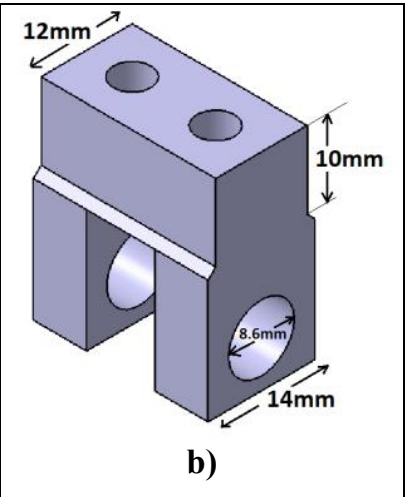

Fig. 5 a) DEMO model support leg, b) Mockup model support leg

The pin represents the anchoring element between support plug and support leg (Fig. 7 (a)). The initial values chosen for its diameter and length are $7 \mathrm{~mm}$ and 14 mm respectively. It has two M3 threaded holes located on its side faces to allow extraction in case of maintenance operations and it is kept in place by two pin lock spotwelded to the leg (Fig. 7 (b)).

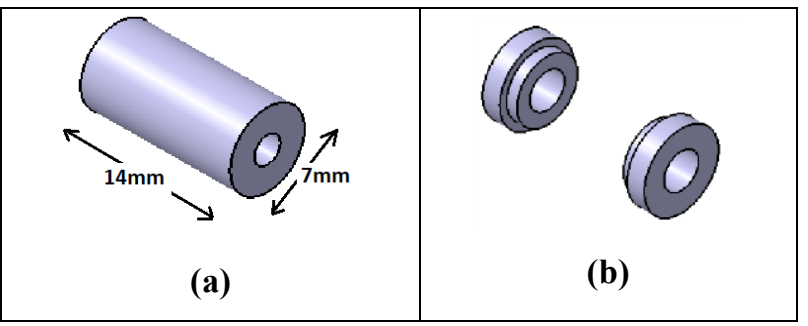

Fig. 6 (a) Pin, (b) Pin Lock

The remaining components represent the electrical insulation system designed inside the support to electrically isolate the PFC from the CB.

The current insulation system foresees that plug and pin are at the same electrical potential while the Leg is at a different potential.

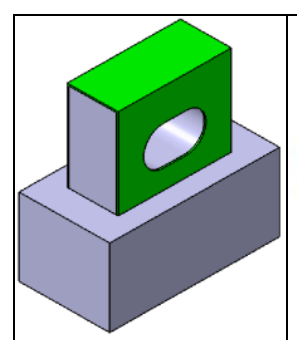

a)

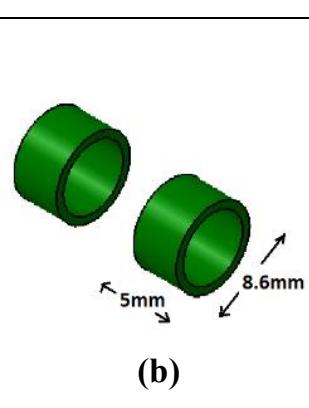

(b)

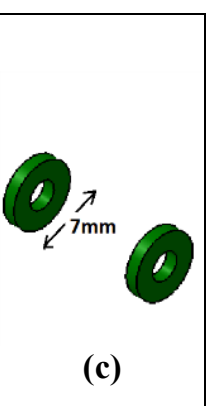

Fig. 7 (a) Plug insulating coating, (b) Insulating bushing, (c) Insulating discs

The side surface of the plug, that is in contact with the inner surface of the leg, is coated with an alumina layer. The current coating thickness is $0.3 \mathrm{~mm}$. (Fig. $7 \mathrm{a}$ ).

Two alumina bushings are foreseen to be inserted in the leg holes to electrically insulate the pin from the leg.
They are $5 \mathrm{~mm}$ wide and $0.8 \mathrm{~mm}$ depth (Fig. $7 \mathrm{~b}$ ).

Alumina discs or alternatively an alumina coating on side faces of the pin are provided to insulate the pin from the pin lock and then from the leg. They are $1 \mathrm{~mm}$ depth and they have a central hole to allow maintenance operations (Fig. $7 \mathrm{c}$ ).

In Fig. 8 there is a section view of the mockup support design with the electrical insulating system.

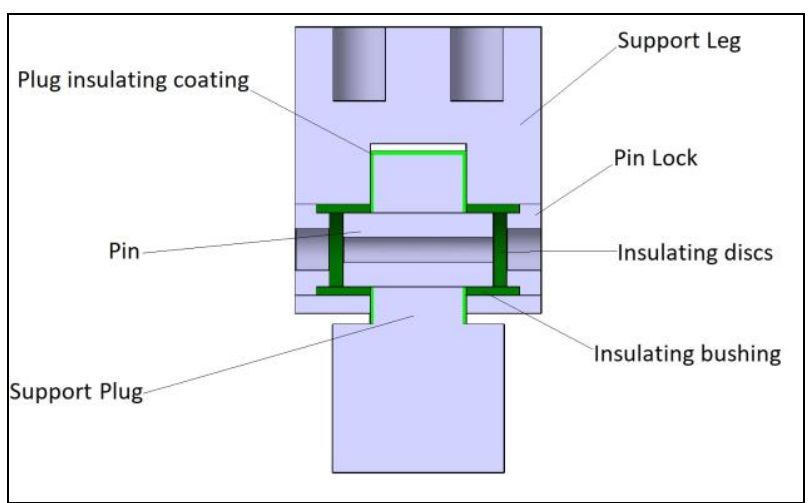

Fig. 8 Support section view with insulating system

\section{Design optimization}

After the realization of the first CAD model a structural verification was carried out by FEM with the Design Exploration package of ANSYS Workbench.

The attention has been focused mainly on the insulation system to have a first estimate of the stresses acting on the ceramic material. For this preliminary design calculation, a simplified structural design technique based on the Weibull theory was taken as a reference for the assessment of ceramic components [12]. The technique includes several steps that lead to the probability of failure of the ceramic component. The initial steps foresee to estimate the critical volume of the ceramic component that is subjected to a tensile stress equal to or greater than $80 \%$ of the maximum tensile stress. The objective of this preliminary analysis was to estimate and to minimize this critical volume inside which the probability of failure increases.

In this respect the reference value taken as limit for the design optimization is $80 \%$ of the alumina maximum tensile stress 214 (Mpa).

Three types of analyses were conducted. First linear elastic structural analysis was performed to provide the first geometry optimization of the model. Afterwards a plastic analysis and a thermo-structural analysis were carried out.

The main material properties and settings of the analysis are summarized below.

The reduced activation steel EUROFER97 is the material chosen for metallic component of the DEMO support model considering its low long-term activation and superior creep and swelling resistance under neutron irradiation [13]. The material chosen for the realization of the mockup support Leg, support Plug, Pin and Pin Lock is austenitic steel type XM-19 (see Tab. 1). The 
insulating components are considered to be made of Aluminum Oxide (Alumina, $\mathrm{Al}_{2} \mathrm{O}_{3} \geq 99.5 \%$, see Tab. 2).

\begin{tabular}{|c|c|c|c|c|c|c|}
\hline $\begin{array}{c}\text { Temp } \\
{ }^{\circ} \mathrm{C}\end{array}$ & $\begin{array}{c}\text { Density } \\
\mathrm{Kg} / \mathrm{m}^{3}\end{array}$ & $\begin{array}{c}\text { Young's } \\
\text { Modulus } \\
\mathrm{E}, \mathrm{GPa}\end{array}$ & $\begin{array}{c}\text { Poisson's } \\
\text { Ratio }\end{array}$ & $\begin{array}{c}\text { Minimum } \\
\text { Yeld } \\
\text { strength } \\
\mathrm{MPa}\end{array}$ & $\begin{array}{c}\text { Thermal } \\
\text { expansion } \\
10^{-6} / K\end{array}$ & $\begin{array}{c}\text { Thermal } \\
\text { conductivity } \\
W / m K\end{array}$ \\
\hline 20 & 7880 & 195 & 0.31 & 380 & 14.7 & 11.1 \\
\hline 100 & 7851 & 189 & 0.31 & 321 & 15.4 & 12.5 \\
\hline 200 & 7812 & 183 & 0.31 & 282 & 16 & 14.2 \\
\hline 300 & 7771 & 176 & 0.31 & 260 & 16.5 & 15.9 \\
\hline 400 & 7729 & 169 & 0.31 & 247 & 16.8 & 17.5 \\
\hline
\end{tabular}

Tab. 1 Xm-19 material properties

\begin{tabular}{|c|c|c|c|c|c|c|}
\hline $\begin{array}{c}\text { Temp } \\
{ }^{\circ} \mathrm{C}\end{array}$ & $\begin{array}{c}\text { Density } \\
\mathrm{Kg} / \mathrm{m}^{3}\end{array}$ & $\begin{array}{c}\text { Young's } \\
\text { Modulus } \\
\mathrm{E}, \mathrm{GPa}\end{array}$ & $\begin{array}{c}\text { Poisson's } \\
\text { Ratio }\end{array}$ & $\begin{array}{c}\text { Tensile } \\
\text { strength } \\
\mathrm{MPa}\end{array}$ & $\begin{array}{c}\text { Thermal } \\
\text { expansion } \\
10^{-6} / K\end{array}$ & $\begin{array}{c}\text { Thermal } \\
\text { conductivity } \\
W / m K\end{array}$ \\
\hline 20 & 3950 & 377 & 0.231 & 267 & 4.8 & 33 \\
\hline 100 & 3949 & 373 & 0.232 & 267 & 5.75 & 29 \\
\hline 200 & 3948 & 369 & 0.233 & 267 & 5.90 & 21 \\
\hline 300 & 3947 & 365 & 0.235 & 267 & 6.40 & 16 \\
\hline 400 & 3945 & 360 & 0.236 & 267 & 6.80 & 13.5 \\
\hline
\end{tabular}

Tab. 2 Alumina material properties

Fig. 9 presents a general view of the mesh used in the analyses. It consists of about $3 \times 10^{5}$ second order solid elements.

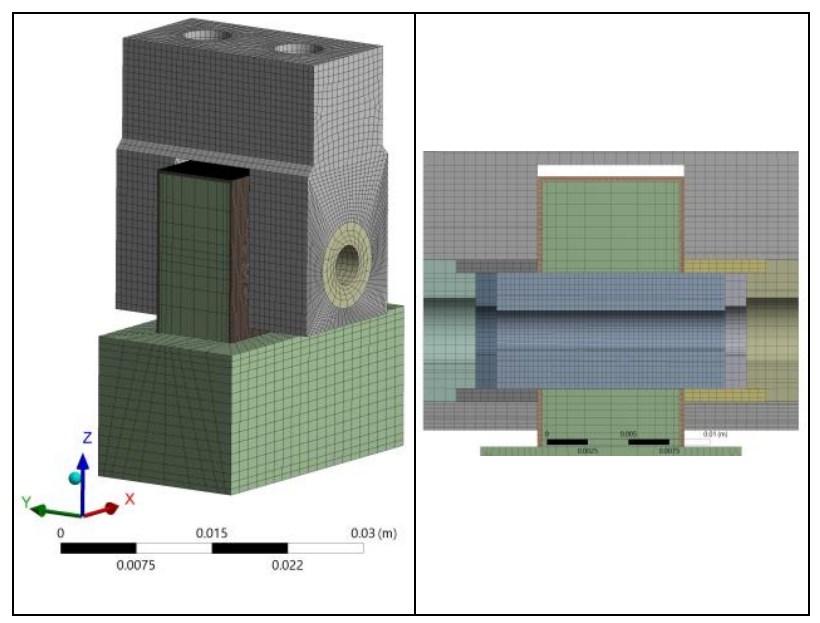

Fig. 9 Mesh overview

Contact element were used to simulate load transfers between the parts. Bonded contact was used between the plug and its alumina coating and between the pin lock and the leg. Frictionless contact was used for the other contacts.

The base of the plug was chosen as a fixed support, while only vertical displacements to the upper surface of the leg were left free.

At the time of this analysis the electromagnetic loads evaluation on the support are underway but reference values are not available. We have therefore chosen a traction load value of $9 \mathrm{kN}$ applied on the upper surface of the Leg taking into account the ITER experience [11] (Fig. 10).

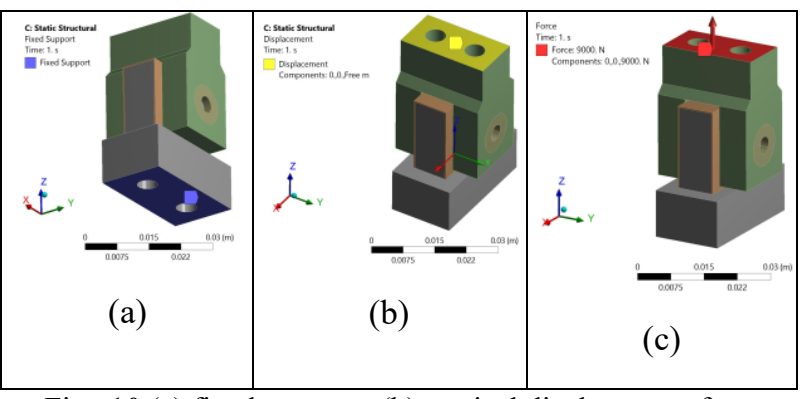

Fig. 10 (a) fixed support, (b) vertical displacement free,

(c) $9 \mathrm{kN}$ traction vertical load

For the thermal analysis an internal heat generation of $5.7 \mathrm{~W} / \mathrm{m}^{3}$ was set taking into account nuclear heating density calculations on the support from [14]. And a reference temperature of $150^{\circ} \mathrm{C}$ and $390^{\circ} \mathrm{C}$ was set respectively on the upper and lower surfaces of the support taking in account studies in [15] and [16] (Fig. 11).

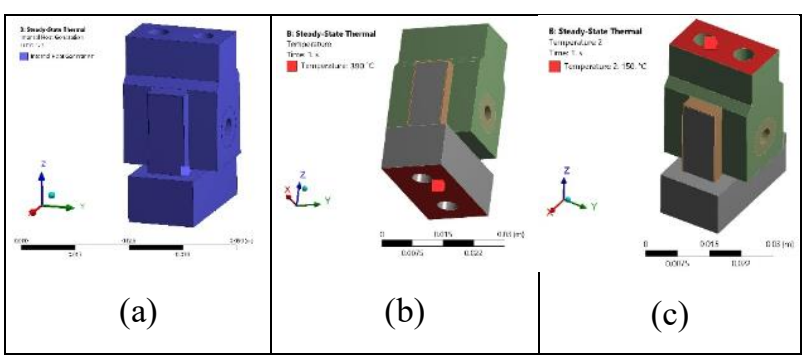

Fig. 11 (a) internal heat generation density of $5.7 \mathrm{~W} / \mathrm{m} 3$,

(b) reference temperature of $390^{\circ} \mathrm{C}$,

(c) reference temperature of $150^{\circ} \mathrm{C}$

\subsection{Linear elastic analysis}

Fig. 12 and Fig. 13 show the results of the first linear elastic analysis on ceramic components.

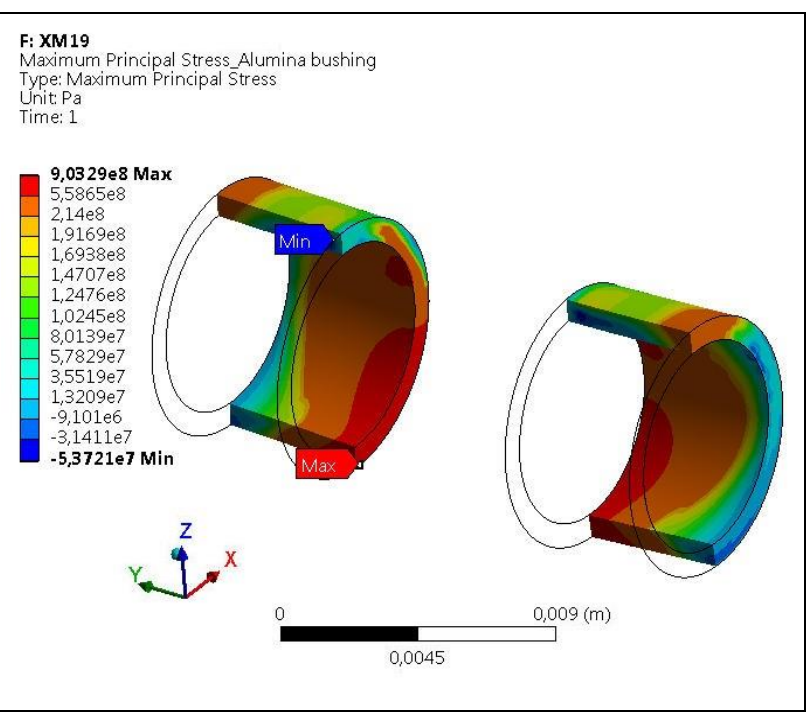

Fig. 12 Linear elastic maximum principal stress on alumina bushing 


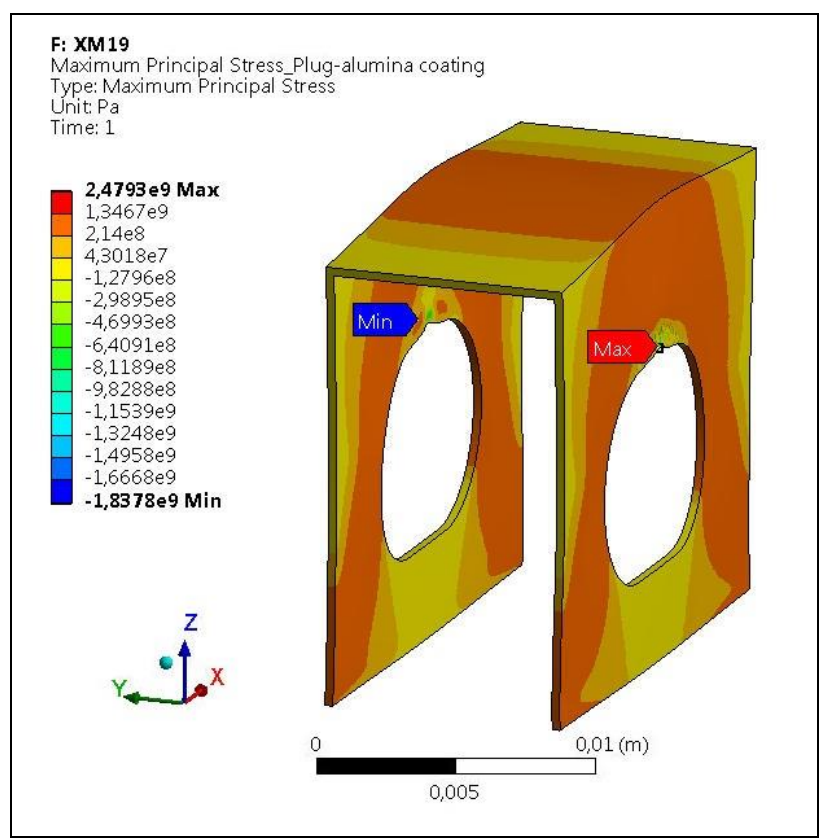

Fig. 13 Linear elastic maximum principal stress on plug alumina coating

In order to reduce the maximum principal stress a parametric analysis was conducted. This resulted in several improvements of the model geometry: the central hole in the pin is removed and the pin diameter and length have been increased to $8 \mathrm{~mm}$ and $18 \mathrm{~mm}$, respectively. Also the size of the support plug and support leg has been increased, in particular around the hole as showed in Fig. 14.

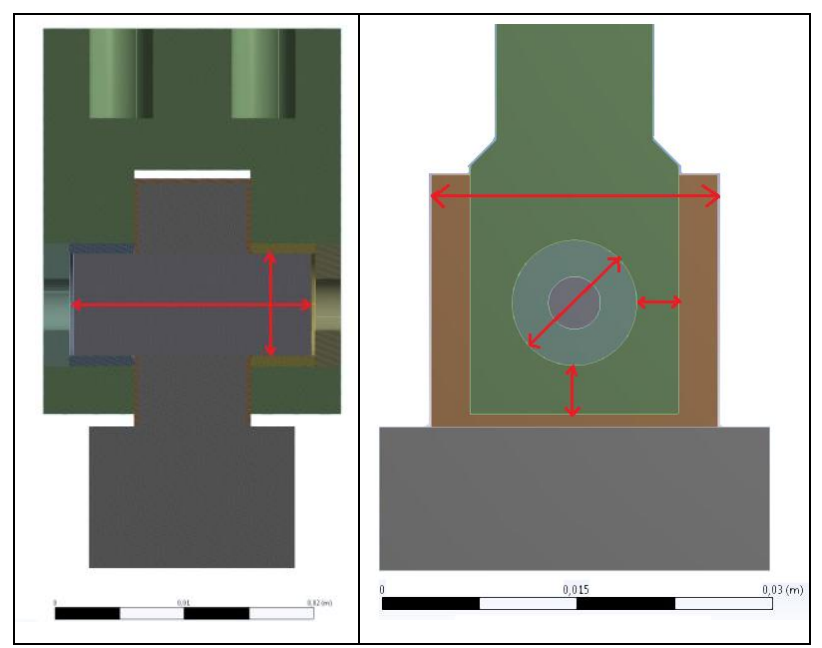

Fig. 14 Design optimization after parametric analysis. In red the increased dimensions

Due to this first optimization the stresses in the ceramic components of the insulation system were reduced to about one quarter of the starting values in the bushings and about one third in the coating as showed in Fig. 15 and Fig. 16.

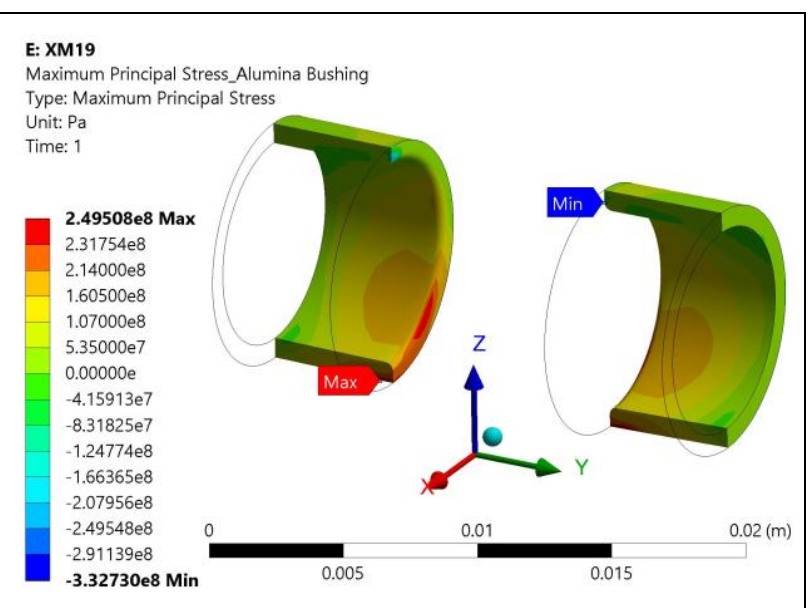

Fig. 15 Linear elastic maximum principal stress on alumina bushing after the design optimization

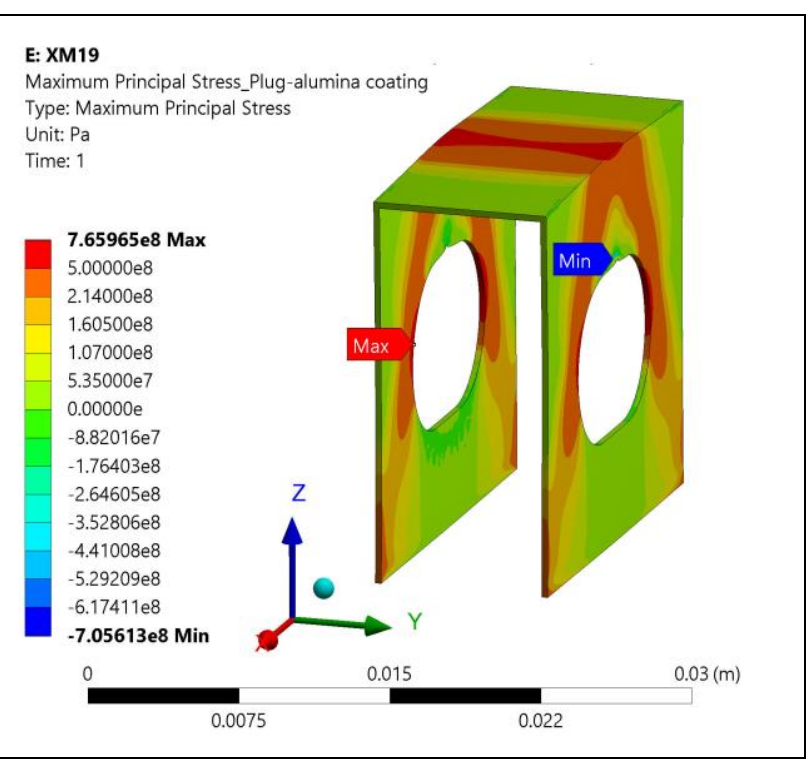

Fig. 16 Linear elastic maximum principal stress on plug alumina coating after the design optimization

\subsection{Elasto-plastic analysis}

After the design optimization an elasto-plastic finite element analysis was conducted applying elastoplastic properties only to metallic material in order to verify how any deformation in the plastic phase of metallic material overload the ceramic components. The main results on ceramic components are summarized in Fig. 17 and Fig. 18. 


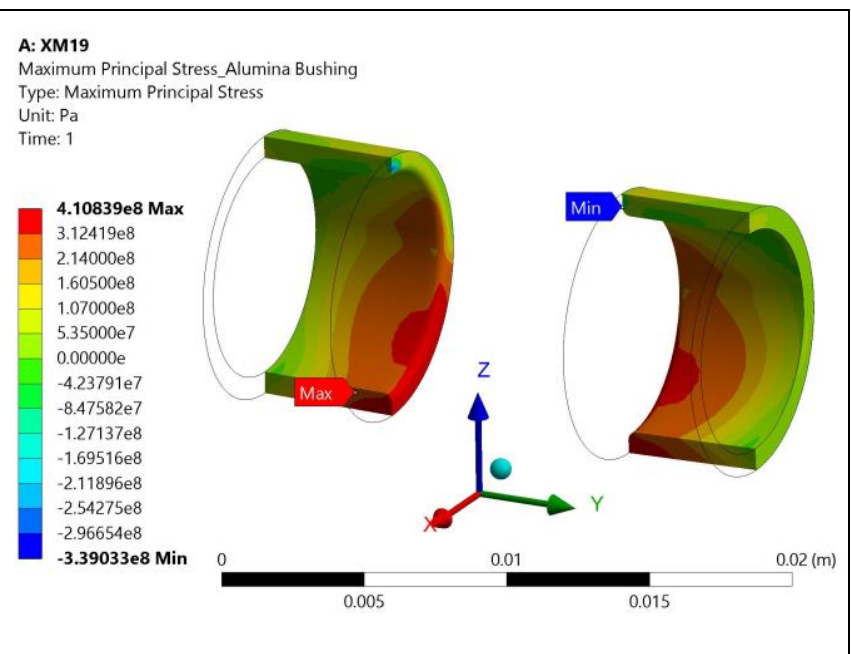

Fig. 17 Elasto-plastic maximum principal stress on alumina bushing

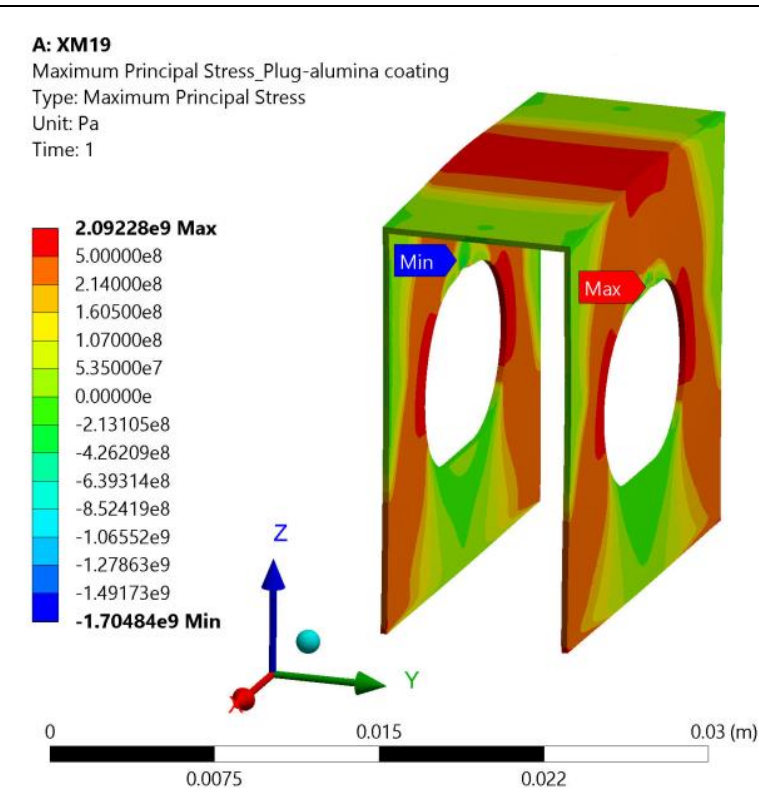

Fig. 18 . Elasto plastic maximum principal stress on plug alumina coating

It can be noticed how the stresses in ceramic component increased again: bigger deformations obtained in the metallic components result in an increase of the stresses on the insulation system.

\subsection{Thermal-structural linear elastic analysis}

The aim of the last linear elastic analysis was to provide a first assessment of the thermal behavior of the support with the ceramic insulating system.

The thermal field on the support mockup is showed in Fig. 19.

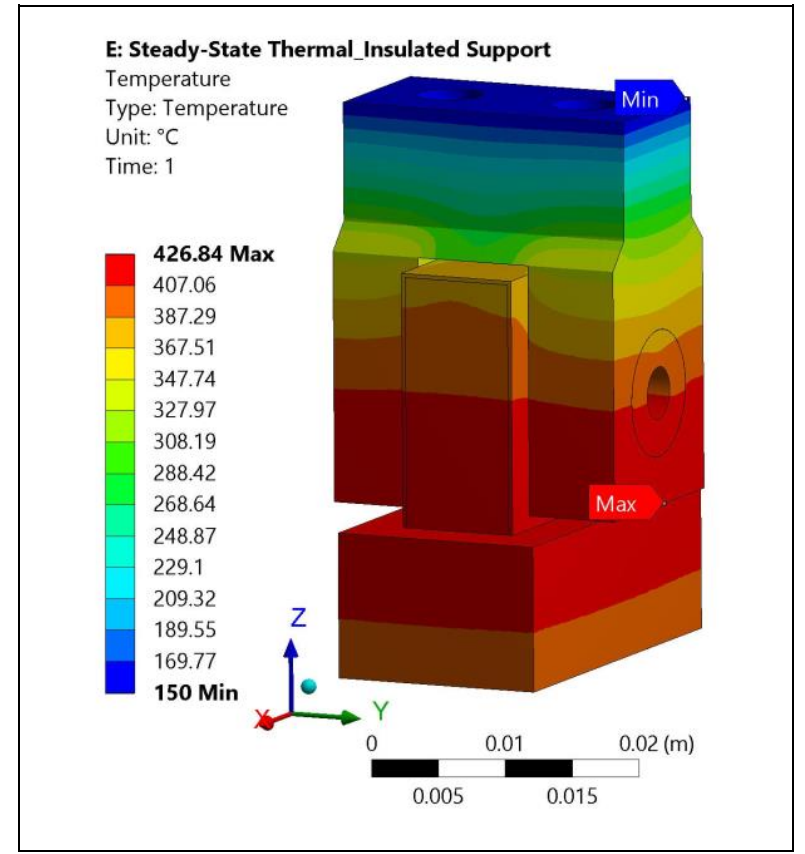

Fig. 19 Resulting support mockup thermal field

As showed in the next figures (Fig. 20, Fig. 21, Fig. $22)$, the resulting thermal expansion generate large stresses on the ceramic component, in particular on the plug alumina coating.

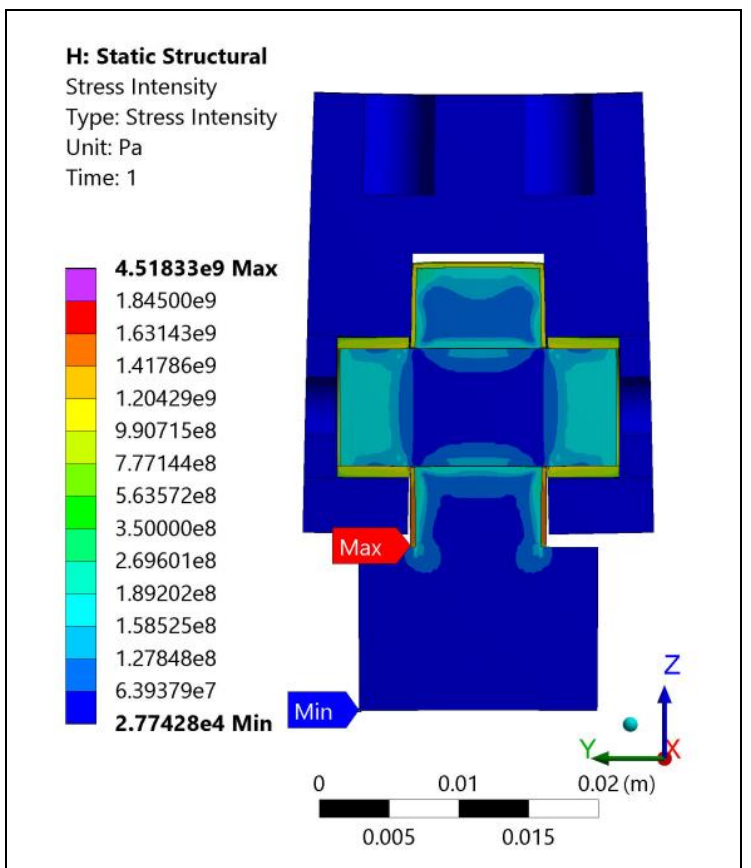

Fig. 20 Support mockup thermal stress Intensity 


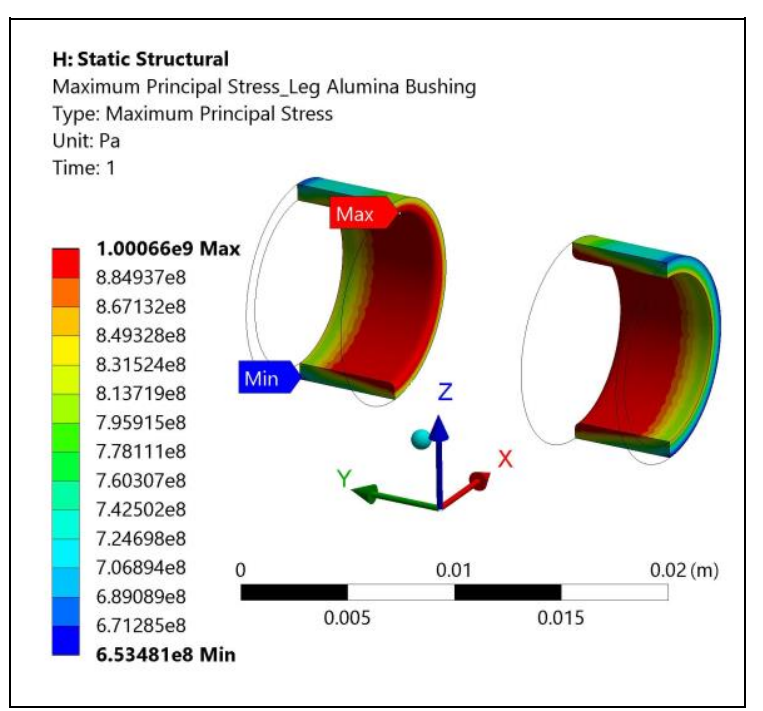

Fig. 21 Alumina bushing thermal stresses

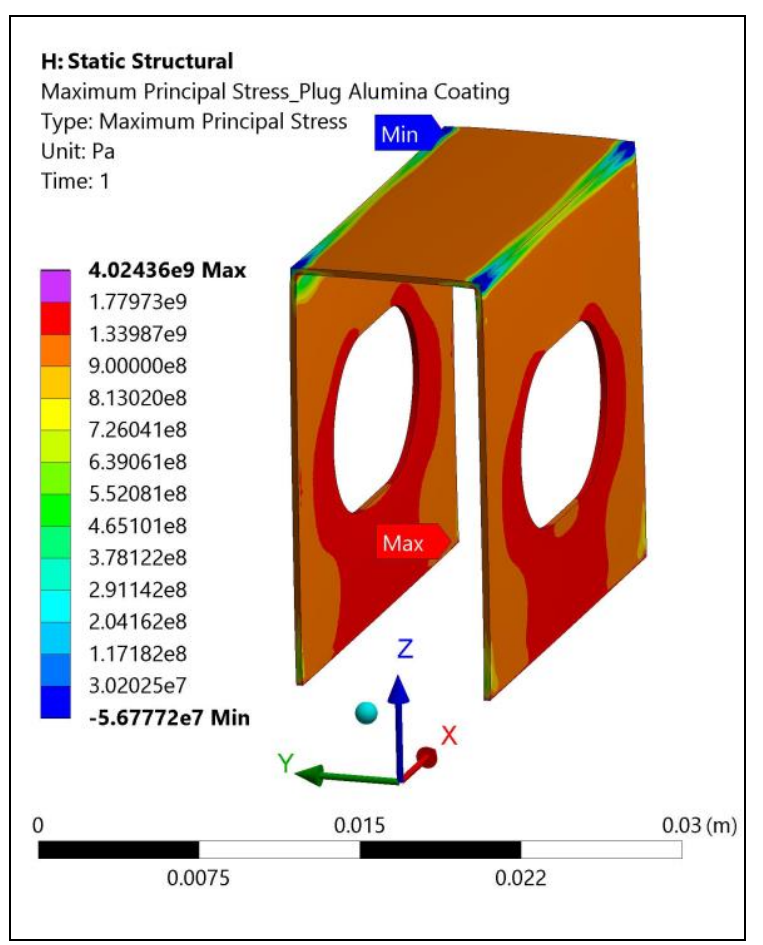

Fig. 22 Plug alumina coating thermal stresses

\section{Conclusion}

A CAD model concept of the PFC-CB support has been developed with an electrical insulating system based on ceramic alumina components.

A first design assessment and optimization has been carried out in order to have a first evaluation of the structural behavior of the insulating system and to reduce the volume fraction of the ceramic component with a tensile stress equal or greater than the $80 \%$ of the alumina maximum tensile stress.
Further studies are planned in order to make the design consistent with the theory of structural ceramic design materials and estimate the reliability of the ceramic components.

\section{Acknowledgments}

This work has been carried out within the framework of the EUROfusion Consortium and has received funding from the Euratom research and training program 20142018 and 2019-2020 under grant agreement No 633053. The views and opinions expressed herein do not necessarily reflect those of the European Commission.

\section{References}

[1] F. Romanelli, P. Barabaschi, D. Borba, G. Federici, L. Horton, R. Neu, D. Stork and H. Zohm - Fusion Electricity: a roadmap to the realisation of fusion energy, EFDA 2012- ISBN 978-3-00-040720-8.

[2] Tony Donné, William Morris - European Research Roadmap to the Realisation Fusion Energy, EUROfusion Programme Management November 2018 - ISBN 978-3-00-061152-0.

[3] Marzullo, D., Bachmann, C., Coccorese, D., Di Gironimo, G., Frosi, P., Mazzone, G., \& You, J. H. (2019). Progress in the pre-conceptual CAD engineering of European DEMO divertor cassette. Fusion Engineering and Design 146, 942-945

[4] Mazzone, G., et al. "Structural verification and manufacturing procedures of the cooling system, for DEMO divertor target (OVT)." Fusion Engineering and Design 146 (2019): 1610-1614.

[5] Marzullo, D., et al. "Systems engineering approach for pre-conceptual design of DEMO divertor cassette." Fusion Engineering and Design 124 (2017): 649-654.

[6] A. Kallenbach, et al., "Optimized tokamak power exhaust with double radiative feedback in ASDEX Upgrade", Nucl. Fusion 52, 122003, 2012.

[7] G. Pautasso, et al., "The halo current in ASDEX Upgrade", Nucl. Fusion 51, 043010, 2011.

[8] Private communication - L. Giannone, et al., "Conceptual study for detachment measurements in DEMO", final report, 2017, EFDA_D_2N6GTP.

[9] S. El Shawish, et. al., "Study of electromagnetic disruption forces for plasma detachment measurements in DEMO", Fus. Eng. Des. 138, 372, 2019.

[10] S. El Shawish, et. al., "Shunt Analysis in the Isolated-Target Divertor Model for Plasma Detachment Measurement in DEMO", under review

[11] F4E-OMF-567 - Annex B - Technical Specification (F4E_D_27MKGH v.1.5)

[12] Herbert Herman - Structural Ceramics - John B. Wachtman, Jr.- Volume 29, Academie Press1989, ISBN: 0-12-341829-1

[13] Mazzone, Giuseppe, et al. "Choice of a low operating temperature for the DEMO EUROFER97 divertor cassette." Fusion Engineering and Design 124 (2017): 655-658.

[14] Private communication - DIV-1-T005-D005 WP 2018 Loads Specification (LS) for Divertor Cassette 2018 (incl. neutronics, EM analysis) (2NLWLE)

[15] Fabio Crescenzi, et al. "Design study of ITER-like divertor target for DEMO" Fusion Engineering and Design Volumes 98-99, October 2015, Pages 1263-1266

[16] Di Maio, P. A., et al. "Computational thermofluid-dynamic analysis of DEMO divertor cassette body cooling circuit." Fusion Engineering and Design 136 (2018): 1588-1592. 